\title{
SELENITE SORPTION BY CARBONATE SUBSTITUTED APATITE
}

Robert C. Moore, Mark J. Rigali, Patrick Brady

Sandia National Laboratories, P.O. Box 5800, Albuquerque, NM 87185, United States of America. Email addresses: rcmoore@sandia.gov, mjrigal@sandia.gov, pvbrady@sandia.gov

Corresponding author: rcmoore@sandia.gov 


\begin{abstract}
The sorption of selenite, $\mathrm{SeO}_{3}{ }^{2-}$, by carbonate substituted hydroxylapatite was investigated using batch kinetic and equilibrium experiments. The carbonate substituted hydroxylapatite was prepared by a precipitation method and characterized by SEM, XRD, FT-IR, TGA, BET and solubility measurements. The material is poorly crystalline, contains approximately $9.4 \%$ carbonate by weight and has a surface area of $210.2 \mathrm{~m}^{2} / \mathrm{g}$. Uptake of selenite by the carbonated hydroxylapatite was approximately an order of magnitude higher than the uptake by uncarbonated hydroxylapatite reported in the literature. Distribution coefficients, $\mathrm{K}_{\mathrm{d}}$, determined for the carbonated apatite in this work ranged from approximately 4,200 to over $14,000 \mathrm{~L} / \mathrm{kg}$. A comparison of the results from kinetic experiments performed in this work and literature kinetic data indicates the carbonated apatite synthesized in this study sorbed selenite 23 times faster than uncarbonated hydroxylapatite based on values normalized to the surface area of each material. The results indicate carbonated apatite is a potential candidate for use as a sorbent for pump-and-treat technologies, soil amendments or for use in permeable reactive barriers for the remediation of selenium contaminated sediments and groundwaters.
\end{abstract}

\title{
Capsule
}

The sorption of selenite by carbonated apatite including distribution coefficeints and kinetic data are reported.

Keywords selenium, selenite, carbonated apatite, apatite, sorption, kinetics 


\section{Introduction}

Selenium occurs naturally in very low amounts, $50-1700 \mu \mathrm{g} / \mathrm{kg}$ sediment, and is ubiquitous in the environment (Parkman and Hultberg, 2002; Preedy and Watson, 2005). Higher concentrations of selenium are from man-made sources including agriculture, mining, and coal ash. Selenium is a nutrient required in small quantities for animals, however, in higher concentration it is highly toxic resulting in selenois or death (Bond, 2000; U.S. G.A.O., 2012). Selenium is easily taken up by plants that are consumed by animals and as a result selenium poisoning has resulted in significant livestock, elk, deer and fish kills (U.S. G.A.O., 2012). Furthermore, Selenium contamination of groundwater is a worldwide problem.

In the environment, selenium can be found in four oxidation states depending on the local redox conditions. Under strong to moderate oxidizing conditions, selenate $\left(\mathrm{SeO}_{4}{ }^{2-}\right)$ is predominant. In mildly reducing conditions, selenite $\left(\mathrm{SeO}_{3}{ }^{2-}\right)$ is the predominant species. Under strongly reducing conditions, the $\mathrm{HSe}^{-}$is the predominant species (Elrashidi et al., 1987; Séby et al., 2001). Selenate and selenite are the most significant species under typical groundwater and surface water conditions and are both very water soluble. However, they are distinctive in that selenate does not absorb extensively to natural materials whereas selenite will sorb weakly to clays and more strongly to Fe and Ca based minerals (Shrimpton et al., 2015). Furthermore, selenites are stable in alkaline to mildly acidic conditions (Shamberger, 1981).

Currently, there are no inexpensive and easily implemented technologies for remediation of selenium contaminated groundwater. Methods to remove selenium from water and groundwater include phytoremediation (Esringü and Turan, 2012), biological 
treatment (Hageman et al., 2013), ion exchange, evaporation, chemical treatment and filtration (Bond, 2000) and permeable reactive barriers (PRB) (Zhang et al., 2008). All of these methods with the exception of using PRB are active treatment technologies that have significant capital costs, create waste streams, can expose workers to the contaminant and have significant long-term operational costs (Moore, 2003; Moore et al., 2004; Naftz et al., 2002). Typically, the reactive media used in PRBs are ion exchange media including activated carbon and natural minerals.

The sorption of selenium is reported for several minerals including calcite (Aurelio et al., 2010; Fujikawa and Fukui, 1997; Heberling et al., 2014), magnesium bearing minerals (Opiso et al., 2016), maghemite (Jordan et al., 2013), hematite and magnetite (Fujikawa and Fukui, 1997), iron oxides (Duc et al., 2003) and apatites (Duc et al., 2003; Monteil-Rivera et al., 1999, 2000). The latter and its ability to sorb selenite is the focus of the current study.

The apatite mineral group consists of calcium phosphate compounds with a hexagonal dipyramidal crystal structure and includes hydroxylapatite, $\mathrm{Ca}_{10}\left(\mathrm{PO}_{4}\right)_{6}(\mathrm{OH})_{2}$. It has long been recognized that the apatite group has strong sorptive properties for many radionuclides, heavy metals and other compounds, and many different substitutions can be made into the apatite structure (Ewing and Wang, 2002; Rakovan and Pasteris, 2015; White et al., 2005).

Monteil-Rivera et al. (1999, 2000) studied the sorption of selenite by hydroxylapatite in batch sorption experiments. The authors report that selenite substitutes into the apatite structure for orthophosphate and that selenium is not exclusively located at the surface of the hydroxylapatite, but also diffused slightly into the structure. The sorption of selenium as selenite by hydroxylapatite, fluorapatite and iron oxides is reported by Duc et al. (2003). In this study, the sorption of selenite by hydroxylapatite is 
shown to be $\mathrm{pH}$ dependent with the highest uptake occurring at a $\mathrm{pH}$ of approximately 8 . Sorption by fluorapatite was not significantly affected by $\mathrm{pH}$ but the total uptake of selenite was 2 to 3 orders of magnitude less than that measured for hydroxylapatite. Furthermore, the authors indicate the mechanism for selenite uptake by sorption to the hydroxylapatite surface followed by substitution for orthophosphate in the crystal structure. They conclude that hydroxylapatite can be used as an additive in engineered permeable reactive barriers for sorption of selenium.

In the studies of Monteil-Rivera et al. (1999) and Duc et al. (2003) the kinetics of selenite uptake by hydroxylapatite is reported to be very slow requiring more than 100 hours to reach equilibrium. This suggests that for areas with rapid groundwater flow, the residence time for selenium contaminated groundwater in a PRB may not be sufficient for complete uptake of selenium. Additionally, pump and teat methods would have to be excessively large.

The present study focuses on the use of carbonated apatite as a sorbent for selenite in batch equilibrium and kinetic experiments. The structure and properties of carbonated apatites differ significantly from hydroxylapatite and these differences may affect selenite uptake. Uptake of selenite by apatite through substitution for orthophosphate can be affected by two factors; dissolution rate of the apatite and rate of substitution of selenite for orthophosphate. Carbonated apatites are reported to have faster dissolution rates and higher solubility than hydroxylapatite (Pan and Darvell, 2010). The mechanism of selenite uptake by carbonated apatite may also be different than for hydroxylapatite. Kolmas et al. (2014) report that the substitution of selenite for orthophosphate occurs with simultaneous decalcification and dehydroxylation in order to maintain a charge 
balance in the hydroxylapatite structure. Alternatively, the substitution of selenite for orthophosphate could also occur with the simultaneous substitution of a monovalent cation such as sodium for calcium into the apatite to maintain a charge balance in the apatite structure. For carbonated apatites, the substitution mechanism could be through the substitution of selenite for carbonate and/or phosphate. However, it is beyond the scope of this paper to determine the mechanism of selenite uptake by carbonated apatite. In this initial study, we examine selenite uptake rates and distribution coefficients and compare the data to literature date for selenite substitution into hydroxylapatite.

\section{Materials and methods}

\section{Carbonate substituted spatite}

All chemicals used were reagent grade. Deionized water used in the work was purified by reverse osmosis followed by filtration through activated carbon. Carbonated apatite was prepared using a modification of the precipitation method described by Frank-Kamenetskaya et al. (2011). A $0.35 \mathrm{~L}$ solution containing $0.053 \mathrm{M} \mathrm{CaNO}_{3}$ was slowly mixed with $0.35 \mathrm{~L}$ of a solution containing $0.0107 \mathrm{M} \mathrm{NaHPO}_{4}$ and $0.021 \mathrm{M}$ $\mathrm{NaHCO}_{3}$ over a $4 \mathrm{hr}$. period in a $1 \mathrm{~L}$ flask thermostated at $32^{\circ} \mathrm{C}$. In this synthesis method the concentration of $\mathrm{NaHPO}_{4}$ is low relative to $\mathrm{NaHCO}_{3}$ to encourage the formation of carbonated apatite. The low temperature precipitation method has been shown produce a poorly crystalline apatite with a high sorption capacity relative to highly crystalline apatites produced by hydrothermal methods (Frank-Kamenetskaya et al., 2011). All solutions were degassed before mixing by sparging with ultrapure argon and the initial $\mathrm{pH}$ of each solution was adjusted to 7.4 using $0.01 \mathrm{M} \mathrm{HCl}$ and/or $0.01 \mathrm{M} \mathrm{NaOH}$ solutions. After the solutions were mixed the resulting slurry was stirred and maintained at $32^{\circ} \mathrm{C}$ for 
an additional 24 hours. The precipitate was removed by vacuum filtration, rinsed with distilled water and dried under vacuum at ambient temperature for 24 hours. The dried precipitate was then ground into a fine powder.

The precipitate was examined using a Bruker D8 Advanced X-Ray Diffractometer (XRD) (scanning at 2 sec. per data point with a 0.02 degree step size), a Thermo-electron Corporation Nicolet FT-IR 380 Fourier Transform-Infrared Spectrometer (FT-IR) and a JEOL Scanning Electron Microscope (SEM). The surface area of the precipitate was determined by Brunauer, Emmett and Teller (BET) analysis using a Micromeritics Instrument Corp. Tristar 3000.

The amount of carbonate in the apatite was determined by thermogravometric analysis (Venkatesan et al., 2015) using a SDT Q600 thermogravimetric analyzer. The carbonated apatite sample was heated to different temperatures and held at each temperature for $30 \mathrm{~min}$. The ramping temperature was $10^{\circ} \mathrm{C}$ per min. Samples were heated to $160^{\circ} \mathrm{C}$ to remove water adsorbed to the carbonated apatite surface, to $400^{\circ} \mathrm{C}$ to remove additional water inside the carbonated apatite structure and finally to $950^{\circ} \mathrm{C}$ to assure that all carbonate in the structure was converted to carbon dioxide. The amount of water and carbonate loss was determined gravimetrically.

\section{Carbonated apatite solubility}

The solubility of the carbonated apatite was determined at $\mathrm{pH}$ values of 5, 6, 9, and 11 . Experiments were performed by placing $40 \mathrm{mg}$ of carbonated apatite in $20 \mathrm{~mL}$ of deionized water and gently agitating the mixtures for 7 days. The $\mathrm{pH}$ of the solutions was measured and, if necessary, adjusted each day with $0.01 \mathrm{M} \mathrm{HCl}$ and/or $0.01 \mathrm{M} \mathrm{NaOH}$. After 5 days no further change in $\mathrm{pH}$ was observed in the mixtures. Samples were 
withdrawn using a syringe, filtered through a $0.40 \mu \mathrm{m}$ syringe filer and acidified with 0.1 $\mathrm{M} \mathrm{HNO}_{3}$. Calcium and phosphate concentrations were then determined by ion chromatography.

\section{Kinetic experiments}

Kinetic experiments were performed by using a batch method. Eighty milligrams of carbonated apatite were added to $40 \mathrm{~mL}$ of solution. The background electrolyte was $0.1 \mathrm{M} \mathrm{KNO}_{3}$ (Duc et al., 2003; Monteil-Rivera et al., 2000). It is known that potassium and nitrate do not strongly interact with apatite, carbonated apatite or selenium. The system was gently agitated on a shaker table and allowed to equilibrate for 7 days prior to initiation of kinetic experiments. This step ensures dissolution is not the limiting process in reaching equilibrium (Monteil-Rivera et al., 2000). The $\mathrm{pH}$ of the mixture was maintained 8.0 by addition of $0.01 \mathrm{M} \mathrm{HCl}$ and/or $0.01 \mathrm{M} \mathrm{KOH}$, if necessary. After 5 days, the $\mathrm{pH}$ of the mixture remained constant. $\mathrm{Na}_{2} \mathrm{SeO}_{3}$ was added to give an initial selenium concentration of $68 \mathrm{mg} / \mathrm{L}$ and the $\mathrm{pH}$ was adjusted daily if necessary. Aliquots of the liquid phase, $0.2 \mathrm{~mL}$, were withdrawn periodically using a syringe, filtered through a 40 $\mu \mathrm{m}$ syringe filter and acidified with $0.01 \mathrm{M} \mathrm{HNO}_{3}$. The amount of selenium in the samples was determined by ICP-MS. Blanks containing only selenite with no carbonated apatite for the kinetic and equilibrium experiments indicated selenium was not sorbing to the containers, syringes or filters.

\section{Equilibrium experiments}

Equilibrium experiments were performed by adding $40 \mathrm{mg}$ of carbonated apatite to $20 \mathrm{~mL}$ solutions of $0.1 \mathrm{M} \mathrm{KNO}_{3}$ in polycarbonate vials. Experiments were performed over a range of $\mathrm{pH}$ from 6 to 12 and at two different initial selenite ion concentrations of 
$6.33 \times 10^{-3} \mathrm{moles} / \mathrm{L}$ and $2.42 \times 10^{-2} \mathrm{moles} / \mathrm{L}$. The carbonated apatite containing solutions were allowed to equilibrate for 7 days prior to adding the selenite and the $\mathrm{pH}$ was adjusted each day if necessary with $0.01 \mathrm{M} \mathrm{NaOH}$ and/or $0.01 \mathrm{M} \mathrm{HCl} . \mathrm{Na}_{2} \mathrm{SeO}_{3}$ was added to each mixture and gently agitated on a shaker table for 5 days. The $\mathrm{pH}$ of each vessel was monitored and adjusted if necessary with $\mathrm{HCL}$ or $\mathrm{NaOH}$. At the end of 5 days, samples of the liquid phase were withdrawn and analyzed.

A single reversibility experiment was performed by combining $80 \mathrm{mg}$ of carbonated apatite with $1.72 \mathrm{mg}$ sorbed selenium in $40 \mathrm{ml}$ of $0.1 \mathrm{M} \mathrm{KNO}_{3}$ solution. The mixture was gently agitated on a shaker table and after 48, 96 and 200 hours the solution phase was analyzed as previously described.

\section{Results and discussion}

\section{Analysis of carbonated apatite}

Figure 1 is an XRD pattern of $2 \theta$ vs. intensity for the carbonated apatite that was scanned from $2 \theta$ of $5^{\circ}$ to $60^{\circ}$. The pattern clearly indicates the poor crystallinity of the material. Poor crystallinity is typical for apatites prepared at low temperature and for highly-substituted material. The peak at $2 \theta=26.8^{\circ}$ corresponds to the (002) plane and the peak between $2 \theta=31^{\circ}$ to $34^{\circ}$ corresponds to the $(211,112$ and 300) planes in the apatite structure. The FT-IR pattern for the carbonated apatite was determined from 500 to 4000 $\mathrm{cm}^{-1}$ and is given in Figure 2. The pattern shown is typical for carbonated apatite with IR vibrational bands for carbonate substituted into the apatite shown at 873 and 1400-1550 $\mathrm{cm}^{-1}$ (LeGeros, 1991). Figure 3 is an SEM image of the carbonated apatite. The material is composed of small irregular shaped sub-micron sized agglomerated particles that are 
typical for carbonated and poorly crystalline hydroxylapatite (LeGeros, 1991). Analysis of the carbonated apatite by the thermogravimetric method indicates the material contains

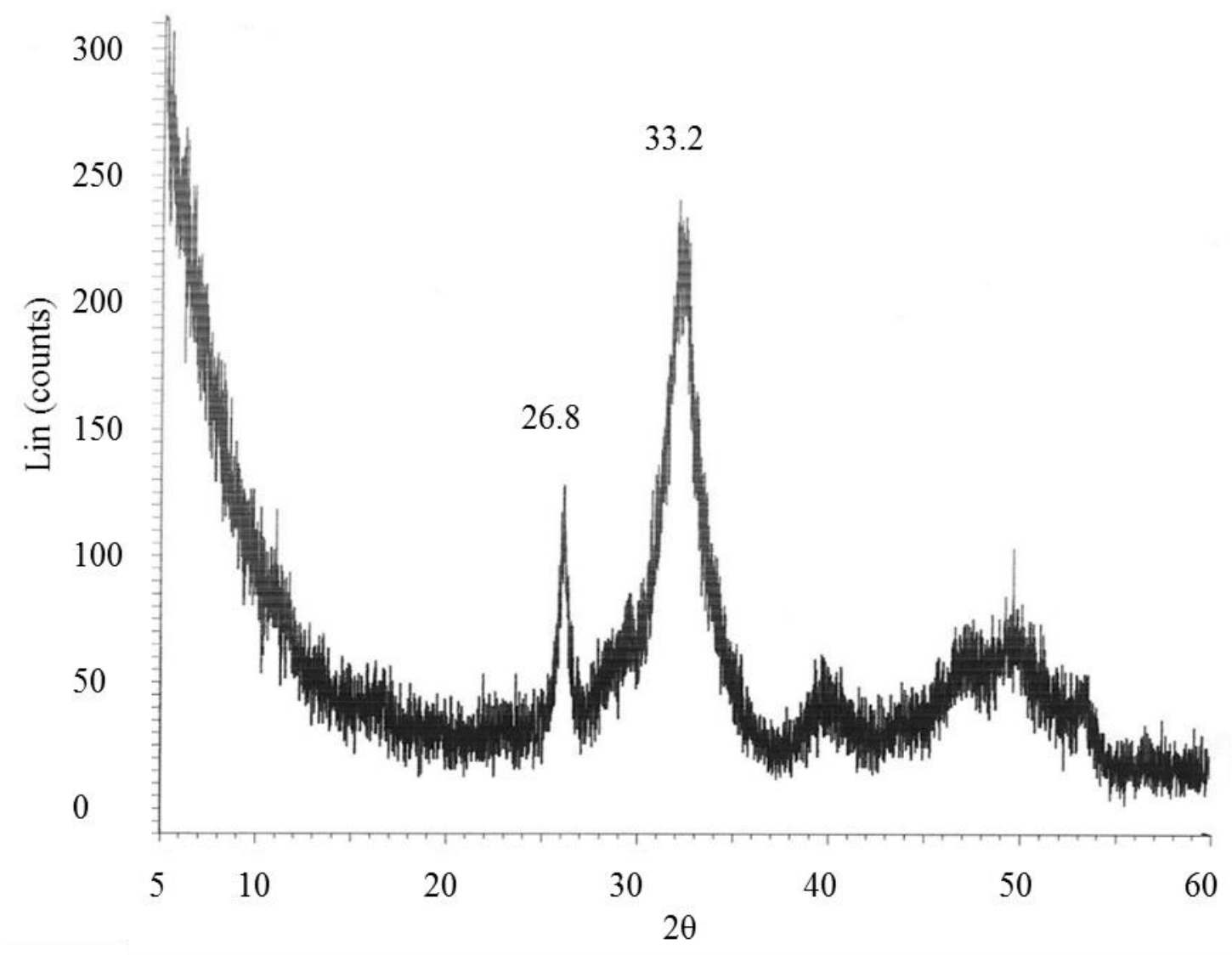

Figure 1. XRD pattern for carbonated apatite prepared in this work. 


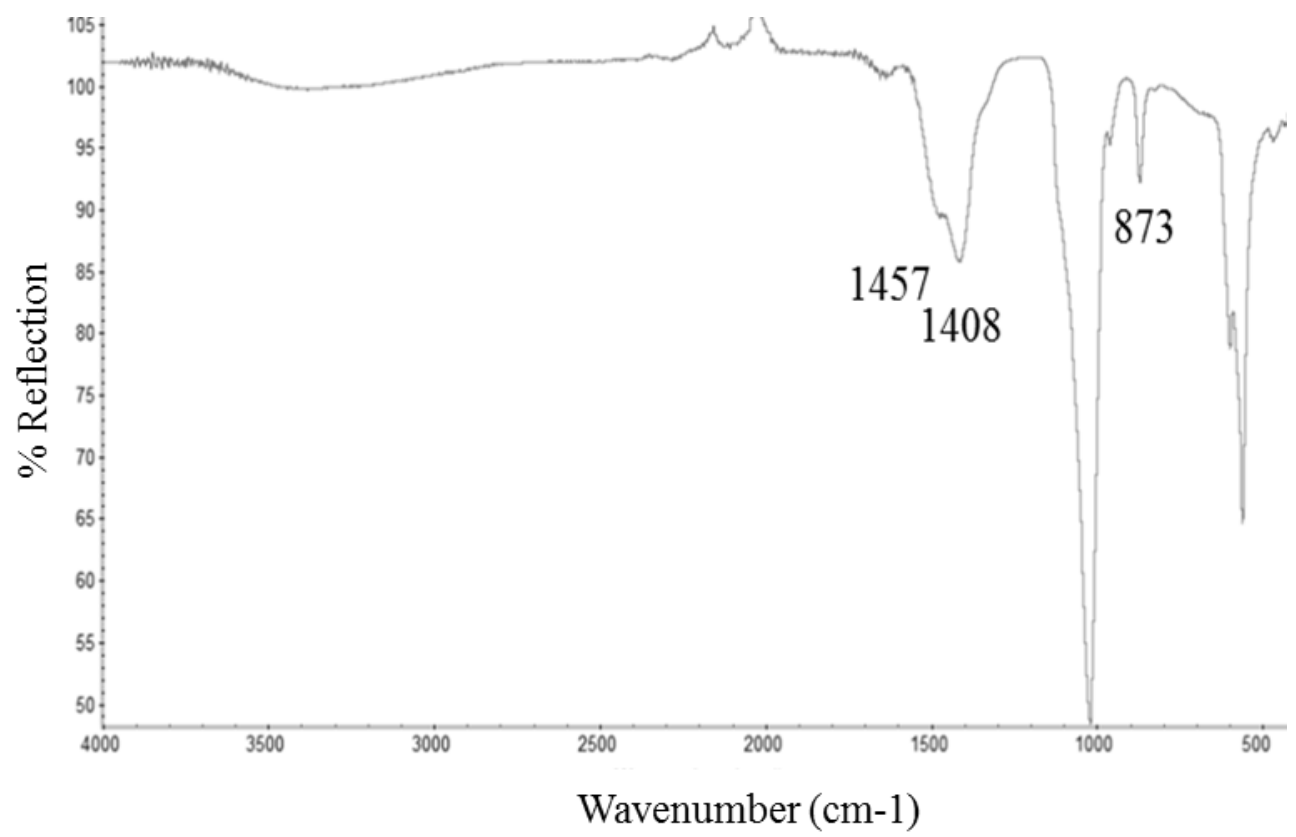

Figure 2. FT-IR pattern of the carbonated apatite.

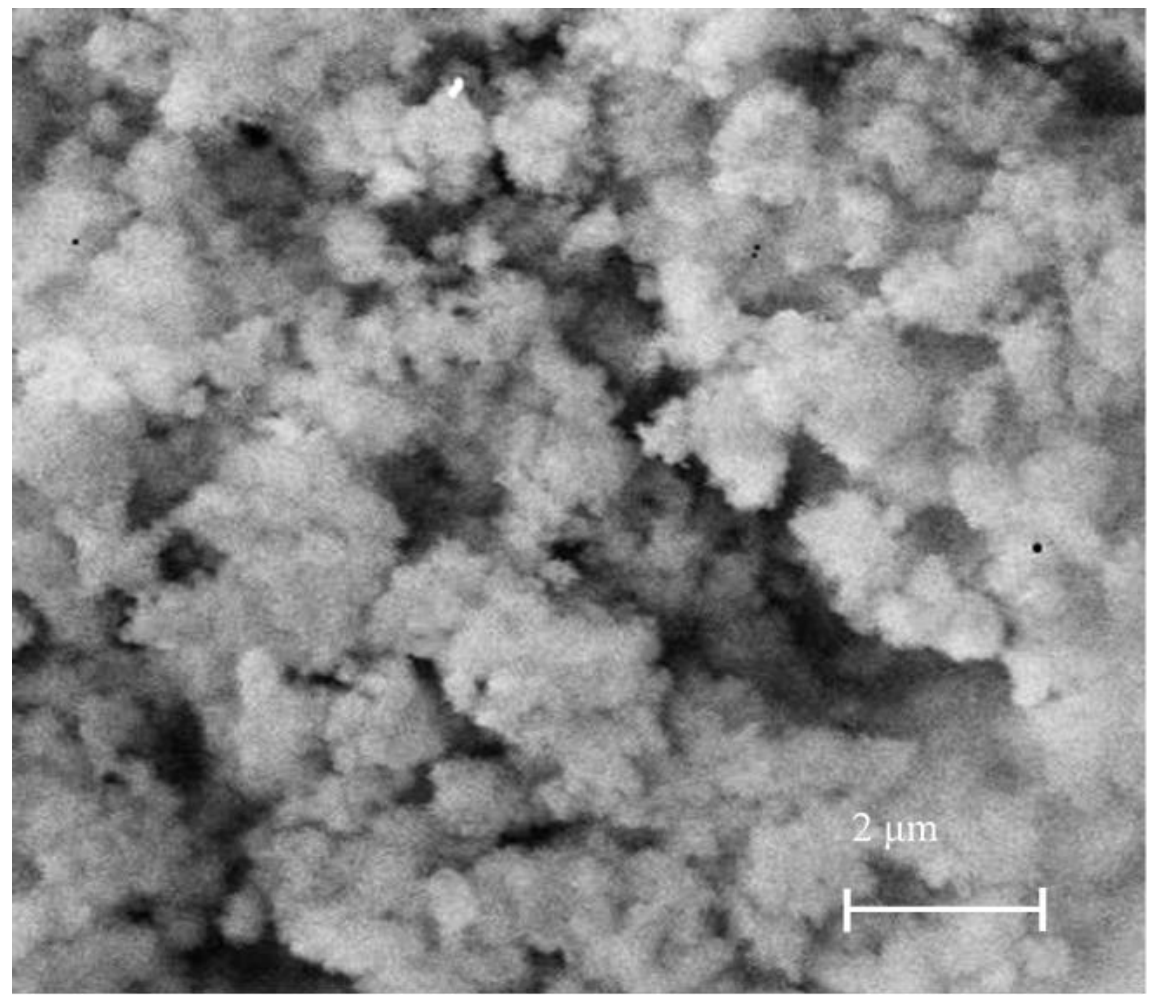

Figure 3. SEM image of the carbonated apatite. 
$6 \%$ water sorbed onto the surface, $3.5 \%$ water in the structure of the material and $9.4 \%$ carbonate that has been substituted for phosphate. BET analysis indicated the material has a surface area of $210.2 \mathrm{~m}^{2} / \mathrm{g}$.

\section{Carbonated apatite solubility}

The solubility of the carbonated apatite is shown in Figure 4 as a plot of calcium and phosphate concentration in solution as a function of $\mathrm{pH}$. The propagated error in each measurement, represented in the figure as error bars, was calculated based on the error in the analytical procedures used, the residual standard deviation reported for the ICP-MS, round off error in calculations. The solubility of the carbonated apatite is relatively high

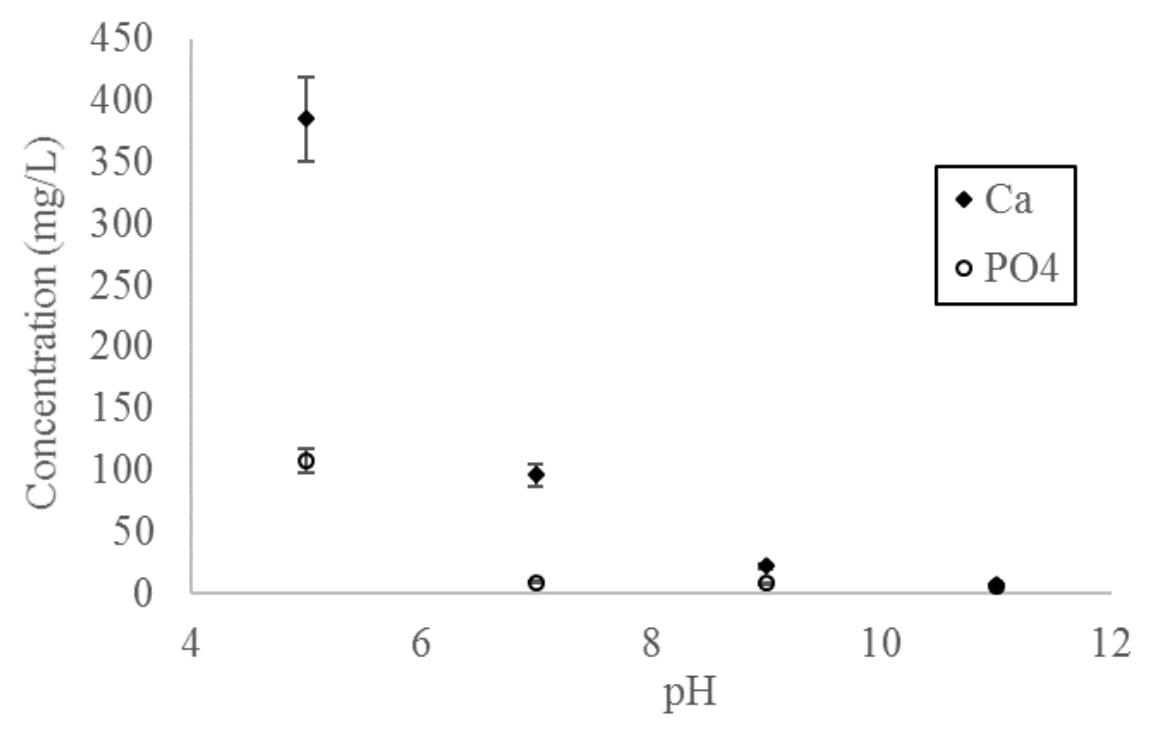

Figure 4. Concentrations of $\mathrm{Ca}$ and $\mathrm{PO}_{4}$ in solution as a function of $\mathrm{pH}$ for carbonated hydroxylapatite in $0.1 \mathrm{M} \mathrm{KNO}_{3}$ 
in acidic solution but rapidly drops off in basic solutions. This is typical for apatites in general (LeGeros, 1991).

For pure hydroxylapatite, solubility values reported in the literature vary widely with significantly higher solubility of apatites in the acidic region. Solubility measurements for hydroxylapatite by Liu et al. (2015) report a $\mathrm{Ca}^{2+}$ concentration of approximately $10 \mathrm{mg} / \mathrm{L}$ at a $\mathrm{pH}$ of 5 . This value is significantly lower than the value reported for carbonated apatite used in our study. The difference can be attributed to several factors. The hydroxylapatite used in the Liu et al. (2015) study was heat treated at $150^{\circ} \mathrm{C}$ for $8 \mathrm{hr}$. prior to use. The carbonated apatite synthesized in this work was heated only to $32^{\circ} \mathrm{C}$. Additionally, the XRD pattern for the Liu et al. (2015) carbonated apatite indicates it is significantly more crystalline than the carbonated apatite used in our study. A comparison of the FT-IR patterns of both materials indicate the carbonated apatite used in our work contains significantly more carbonate than the material used by Liu et al. (2015). All of these factors can significantly affect solubility as discussed by LeGeros (1991) and Pan and Darvell (2010).

\section{Selenium sorption experiments}

\section{Kinetic experiments}

A kinetic experiment was performed to determine the time required to reach equilibrium between selenite taken up by carbonated apatite and that remaining in solution. This information is required to determine the correct parameters for performing equilibrium experiments. The results from the kinetic experiment are given graphically in Figure 5 as a plot of selenium in solution vs. time. The propagated error in each 
measurement is represented by the error bars. Uptake of selenium was complete in approximately $300 \mathrm{~min}$. with $1.72 \mathrm{mg}$ selenium sorbed by $80 \mathrm{mg}$ carbonated apatite.

No other data for selenium uptake by highly carbonated apatite could be located in the literature. However, the data can be compared to data by Monteil-Rivera et al. (1999) for the uptake of selenite by hydroxlapatite. In their study, the researchers used a commercially available hydroxylapatite from Bio-Rad Laboratories. The authors provide two limiting formulae for their hydroxylapatite:

$$
\begin{gathered}
\mathrm{Ca}_{9.3} \mathrm{Na}_{0.48}\left(\mathrm{PO}_{4}\right)_{6}(\mathrm{OH})_{1.1} \cdot 12 \mathrm{H}_{2} \mathrm{O} \\
\mathrm{Ca}_{9.9} \mathrm{Na}_{0.048}\left(\mathrm{PO}_{4}\right)_{5.1}\left(\mathrm{HPO}_{4}\right)_{0.9}(\mathrm{OH})_{2} \cdot 1.8 \mathrm{H}_{2} \mathrm{O}
\end{gathered}
$$

Their kinetic experiments were performed with a solution to solid ratio of 250 $\mathrm{mL} / \mathrm{g}$ with initial selenium concentrations of $1 \times 10^{-3}$ and $1 \times 10^{-5}$ molar.

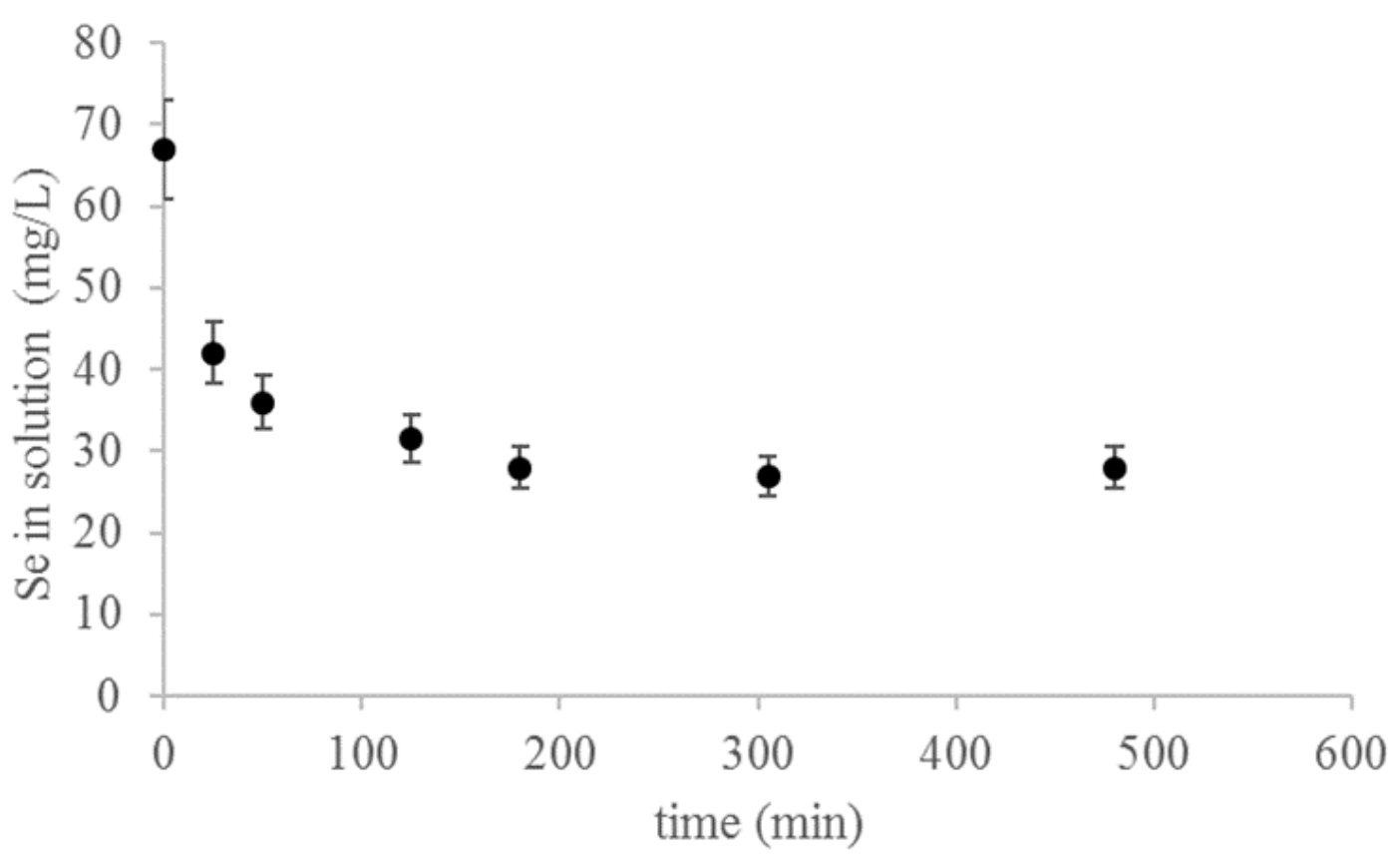


Fgure 5. Sorption of selenium (IV) as a function of time in minutes (min.). $80 \mathrm{mg}$ of carbonated apatite was placed in $40 \mathrm{~mL}$ of $0.1 \mathrm{M} \mathrm{NKO}_{3}$ solution. Initial selenium concentration was $67 \mathrm{mg} / \mathrm{L}$. Selenium in the solution phase was determined by ICP-MS.

With an initial selenite concentration of $1 \times 10^{-3} \mathrm{~mol} / \mathrm{L}$, the authors report approximately $1.27 \mathrm{mg}$ of selenium was sorbed by $100 \mathrm{mg}$ hydroxylapatite in 100 hours. In this work, $1.72 \mathrm{mg}$ of selenium was sorbed by $80 \mathrm{mg}$ carbonated apatite in approximately $300 \mathrm{~min}$. A direct comparison between the two studies is complicated because factors other than carbonate substitution must be considered. These include apatite solubility, the presence of other ions in the apatite structure, surface area and experimental conditions. The data are best compared by normalization to the mass of sorbent. In the Monteil-Rivera et al. (1999) study the total mass uptake of selenium is reported to be $12.7 \mathrm{mg} / \mathrm{g}$ with an uptake rate of $0.127 \mathrm{mg} / \mathrm{g} \mathrm{hr}$. In the present work, the carbonated apatite had a total uptake of $21.5 \mathrm{mg} / \mathrm{g}$ at a rate of $4.3 \mathrm{mg} / \mathrm{g} \mathrm{hr}$. The total amount of Se sorbed is approximately two times more for the carbonated apatite than for the hydroxyapatite used by Monteil-Rivera et al. (1999). Additionally, the kinetics are significantly faster with the carbonated apatite being twenty times faster than what is reported for the hydroxylapatite. These large differences may be attributed not only to differences in experimental conditions and physical and chemical properties of the sorbents but also to different mechanisms of selenite uptake.

\section{Equilibrium experiments}

The equilibrium data was used to calculate distribution coefficients, $K_{\mathrm{d}}$, values, defined as:

$$
K_{\mathrm{d}}=[\mathrm{Se}]_{\text {sorbed }} /[\mathrm{Se}]_{\text {liquid phase }}
$$


Where $[\mathrm{Se}]_{\text {sorbed }}$ and $[\mathrm{Se}]_{\text {liquid phase }}$ are the amount of selenium sorbed $(\mathrm{mg} \mathrm{Se}$ sorbed $/ \mathrm{kg}$ carbonated apatite) and the amount of selenium in the liquid phase (mg Se in the liquid phase/L of solution), respectively.

Figure 6 gives the $K_{\mathrm{d}}$ values plotted as a function of $\mathrm{pH}$ for two different initial selenium concentrations of $6.33 \times 10^{-3} \mathrm{M}$ and $2.42 \times 10^{-2} \mathrm{M}$. The error bars represent the propagated error in each measurement. Maximum selenium sorption occurs between $\mathrm{pH}$ 8.5 and 9 and drops off as the solution is more acidic and basic regions.

Sorption of selenium in the Monteil-Rivera et al. (2000) study occurs with a maximum at pH 7.8 to 8.0 with $K_{\mathrm{d}}$ values of $200 \mathrm{~L} / \mathrm{mol}(182 \mathrm{~L} / \mathrm{kg})$ and $800 \mathrm{~L} / \mathrm{mol}(729$ $\mathrm{L} / \mathrm{kg}$ ) for initial selenium concentrations of $1 \times 10^{-3}$ moles $/ \mathrm{L}$ and $1 \times 10^{-6} \mathrm{moles} / \mathrm{L}$, respectively. In the present study, the maximum selenite sorption is observed between $\mathrm{pH}$

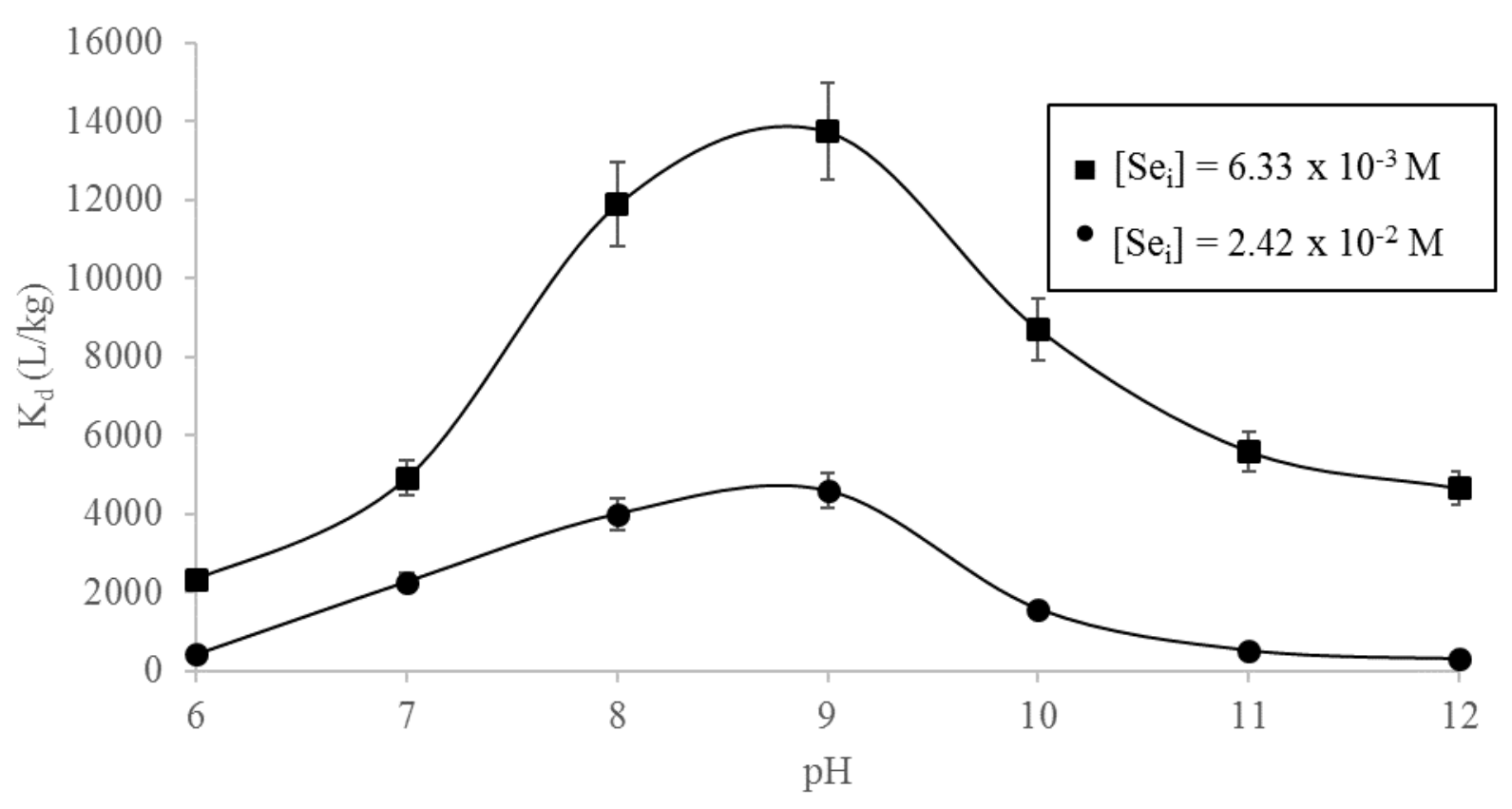

Figure 6. Distribution coefficient, $\mathrm{K}_{\mathrm{d}}$, as a function of $\mathrm{pH}$ for selenite uptake by carbonated apatite. 
8.5 and 9.0 with $K_{\mathrm{d}}$ values of 4,200 L/kg and 14,000 L/kg for initial selenium

concentrations of $2.42 \times 10^{-2}$ moles/L and $6.33 \times 10^{-3}$ moles/L, respectively. If the $\mathrm{K}_{\mathrm{d}}$ values in this work and the work the Monteil-Rivera et al. (2000) for hydroxylapatite are normalized to the mass of sorbent or surface area of sorbent, the $K_{d}$ values measured in this work for carbonated apatite are still an order of magnitude larger.

A single reversibility experiment was performed by placing $80 \mathrm{mg}$ of carbonated apatite with $1.72 \mathrm{mg}$ sorbed selenium in $40 \mathrm{ml}$ of $0.1 \mathrm{M} \mathrm{KNO}_{3}$ solution. After 48 and 96 hours $0.0652 \mathrm{mg}$ and $0.0812 \mathrm{mg}$ of selenium was released into solution. These values correspond to $3.7 \%$ and $4.7 \%$, respectively. After 96 hours and at 200 hrs. no additional release of selenium was detected.

The kinetic and equilibrium data for carbonated apatite indicate it outperforms hydroxylapatite for selenite uptake in experiments performed under similar conditions reported in the literature. However, to identify the mechanism resulting in faster kinetics and increased uptake of selenite by the carbonated apatite will require additional experiments. Unfortunately, the concentration of selenium sorbed by the carbonated apatite is too low for accurate analysis using the analytical instruments and techniques available to us at the time of this work. Future experiments will be performed with more sensitive analytical methods.

\section{Conclusions}

In this work, a poorly crystalline carbonated apatite containing approximately 9.4\% carbonate was synthesized by a precipitation method and characterized by multiple analytical methods. Batch kinetic and equilibrium experiments indicate carbonated apatite uptakes selenite more effectively and significantly faster than that reported for 
hydroxylapatite in the literature. The results indicate carbonated apatite may be a better candidate than hydroxylapatite for remediation of selenium contaminated sites in pump and treat operations, permeably reactive barriers and as a soil amendment. The next phase of this work will be to investigate selenium uptake and desorption from carbonated apatite under varying chemical conditions as well as to determine the mechanism of selenite uptake by carbonated apatite.

\section{Acknowledgements}

Sandia National Laboratories is a multi-program laboratory managed and operated by Sandia Corporation a wholly owned subsidiary of Lockheed Martin Corporation, for the U.S. Department of Energy's National Nuclear Security

Administration under contract DE-AC04-94AL85000.

\section{Declaration of interest}

The authors have no conflict of interest to declare.

\section{Funding}

This work was supported by Sandia National Laboratories, P.O. Box 5800, Albuquerque, NM 87185 


\section{References}

Aurelio, G., Fernández-Martínez, A., Cuello, G.J., Román-Ross, G., Alliot, I., Charlet, L., 2010. Structural study of selenium(IV) substitutions in calcite. Chemical Geology $270,249-256$.

Bond, M.M., 2000. Characterization and Control of Selenium Releases from Mining in the Idaho Phosphate Region. M.S. Thesis. University of Idaho.

Duc, M., Lefevre, G., Fedoroff, M., Jeanjean, J., Rouchaud, J.C., Monteil-Rivera, F., Dumonceau, J., Milonjic, S., 2003. Sorption of selenium anionic species on apatites and iron oxides from aqueous solutions. Journal of Environmental Radioactivity 70, 61-72.

Elrashidi, M., Adriano, D., Workman, S., Lindsay, W., 1987. Chemical equilibria of selenium in soils: a theoretical development. Soil Science 144, 141-152.

Esringü, A., Turan, M., 2012. The roles of diethylenetriamine pentaacetate (DTPA) and ethylenediamine disuccinate (EDDS) in remediation of selenium from contaminated soil by brussels sprouts. Water, Air, and Soil Pollution 223, 351362.

Ewing, R.C., Wang, L., 2002. Phosphates as nuclear waste forms. Reviews in Mineralogy and Geochemistry 48, 673-699.

Frank-Kamenetskaya, O., Kol’tsov, A., Kuz’mina, M., Zorina, M., Poritskaya, L., 2011. Ion substitutions and non-stoichiometry of carbonated apatite-(CaOH) synthesised by precipitation and hydrothermal methods. Journal of Molecular Structure 992, 9-18. 
Fujikawa, Y., Fukui, M., 1997. Radionuclide sorption to rocks and minerals: effects of $\mathrm{pH}$ and inorganic anions. Part 2. Sorption and speciation of selenium. Radiochimica Acta 76, 163-174.

Hageman, S.P., Van der Weijden, R.D., Weijma, J., Buisman, C.J., 2013. Microbiological selenate to selenite conversion for selenium removal. Water Research 47, 2118-2128.

Heberling, F., Vinograd, V.L., Polly, R., Gale, J.D., Heck, S., Rothe, J., Bosbach, D., Geckeis, H., Winkler, B., 2014. A thermodynamic adsorption/entrapment model for selenium (IV) coprecipitation with calcite. Geochimica Acta 134, 16-38.

Jordan, N., Ritter, A., Foerstendorf, H., Scheinost, A.C., Well, S., Heim, K., Grenzer, J., Mücklich, A., Reuther, H., 2013. Adsorption mechanism of selenium(VI) onto maghemite. Geochimica et Cosmochimica Acta 103, 63-75.

Kolmas, J., Oledzka, E., Sobczak, M., Nalecz-Jawecki, G., 2014. Nanocrystalline hydroxyapatite doped with selenium oxyanions: a new material for potential biomedical applications. Materials Science and Engineering C 39, 134-142.

LeGeros, R.Z., 1991. Calcium Phosphates in Oral Biology and Medicine. Karger Press, Basel.

Liu, Q., Matinlinna, J.P., Chen, Z., Ning, C., Ni, G., Pan, H., Darvell, B.W., 2015. Effect of thermal treatment on carbonated hydroxyapatite: morphology, composition, crystal characteristics and solubility. Ceramics International 41, 6149-6157.

Monteil-Rivera, F., Fedoroff, M., Jeanjean, J., Minel, L., Barthes, M.G., Dumonceau, J., 2000. Sorption of selenite $\left(\mathrm{SeO}_{3}{ }^{2-}\right)$ on hydroxyapatite: an exchange process. Journal of Colloid and Interface Science 221, 291-300. 
Monteil-Rivera, F., Masset, S., Dumonceau, J., Fedoroff, M., Jeanjean, J., 1999. Sorption of selenite ions on hydroxyapatite. Journal of Materials Science Letters 18, 11431145.

Moore, R.C., 2003. Situ Formation of Apatite for Sequestering Radionuclides and Heavy Metals. U.S. Patent 6,592,294.

Moore, R.C., Sanchez, C., Holt, K., Zhang, P., Xu, H., Choppin, G.R., 2004. Formation of hydroxyapatite in soils using calcium citrate and sodium phosphate for control of strontium migration. Radiochimica Acta 92, 719-723.

Naftz, D., Morrison, S.J., Fuller, C.C., Davis, J.A., 2002. Handbook of Groundwater Remediation Using Permeable Reactive Barriers: Applications to Radionuclides, Trace Metals, and Nutrients. Academic Press, Orlando, FL.

Opiso, E.M., Sato, T., Yoneda, T., 2016. Immobilization of selenium by Mg-bearing minerals and its implications for selenium removal from contaminated water and wastewater. Applied Clay Science 123, 121-128.

Pan, H., Darvell, B.W., 2010. Effect of carbonate on hydroxyapatite solubility. Crystal Growth \& Design 10, 845-850.

Parkman, H., Hultberg, H., 2002. Occurrence and Effects of Selenium in the Environment: A Literature Review.. Swedish Environmental Research Institute. IVLReport B1486.

Preedy, V.R., Watson, R.R., 2005. Reviews in Food and Nutrition Toxicity. CRC Press, Boca Raton, FL, pp. 36-37. 
Rakovan, J.F., Pasteris, J.D., 2015. A technological gem: materials, medical, and environmental mineralogy of apatite. Elements 11, 195-200.

Séby, F., Potin-Gautier, M., Giffaut, E., Borge, G., Donard, O.F.X., 2001. A critical review of thermodynamic data for selenium species at $25^{\circ} \mathrm{C}$. Chemical Geology $171,173-194$.

Shamberger, R.J., 1981. Selenium in the environment. Science of the Total Environment $17,59-74$.

Shrimpton, H.K., Blowes, D.W., Ptacek, C.J., 2015. Fractionation of selenium during selenate reduction by granular zerovalent iron. Environmental Science and Technology 49, 11688-11696.

United States Government Accounting Office (GAO) Phosphate Mining. Oversight has Strengthened, but Financial Assurances and Coordination Still Need Improvement. May 2012 GAO-12-505.

Venkatesan, J., Lowe, B., Manivasagan, P., Kang, K.H., Chalisserry, P.E., Anil, S., Kim, G.D., Kim, S.K., 2015. Isolation and characterization of nano-hydroxyapatite from salmon fish bone. Materials 8, 5426-5439.

White, T., Ferraris, C, Kim, J. 2005. Apatite - An adaptive framework structure. Reviews in Minerology \&Geochemistry 57, 307-401

Zhang, Y., Amrhein, C., Chang, A., Frankenberger, W.T., 2008. Effect of zero-valent iron and a redox mediator on removal of selenium in agricultural drainage water. Science of the Total Environment 407, 89-96. 